\title{
Journal of global optimization: continuing the tradition of excellence
}

\author{
Sergiy Butenko
}

Received: 1 November 2012 / Accepted: 5 November 2012 / Published online: 18 November 2012

C) Springer Science+Business Media New York 2012

These are exciting times for the field of Global Optimization and for the Journal of Global Optimization (JOGO). Thanks to the outstanding leadership of Panos Pardalos and the excellent service of the editorial board members, JOGO has become one of the representative journals of the field and is well-regarded for its high quality. With the number of submissions and impact indicators significantly increasing during the past several years and the introduction of the best paper award to be granted annually, the future looks very bright for the journal.

As the new Editor-in-Chief of JOGO, I would like to express my gratitude to Professor Pardalos, all current and former members of the editorial board, and the staff of Springer for their commendable efforts in building up the journal's reputation. I appreciate having the opportunity to serve the global optimization community in this important capacity. It is a great honor and, at the same time, a great responsibility, which I am enthusiastically committed to fulfill to the best of my ability.

Nowadays, authors have an unprecedented variety of choices when it comes to deciding on the outlets for publishing their work. To ensure that JOGO remains competitive in attracting top quality contributions, we will aim at

- adhering to consistently high acceptance standards;

- providing timely and professional reviews to the authors;

- increasing the visibility of the journal in the scientific community.

To implement these objectives, it is essential that the diversity of methods and applications covered by the journal, which evolves over time, is adequately reflected in the editorial board composition. Hence, together with the current board members, we will constantly work on enhancing the editorial board to mirror the latest trends in the field and to facilitate a rigorous and efficient handling of submissions. To help the journal's visibility, we will continue attracting surveys on important topics written by leading researchers, as well as publishing

S. Butenko $(\square)$

Texas A\&M University, College Station, TX, USA

e-mail: butenko@tamu.edu 
special issues in conjunction with international workshops and symposia. I look forward to serving the journal and working with everyone interested in the continuing success of JOGO. 